\title{
Pemanfaan Neurosains dalam Desain Pengembangan Kurikulum Bahasa Arab
}

\author{
Muhammad Ilfan Fauzi \\ Universitas Islam Negeri (UIN) Sunan Kalijaga Yogyakarta \\ muhammadilfanfauzi@gmail.com
}

\begin{abstract}
This paper discusses the contribution of neuroscience in the development of the Arabic language curriculum of the modern era with the development of a very strategic and practical reconstruction. One of them is the emergence of integration between nation, brain based learning, and character building using a neuroscience approach. The basic point of this study is the right brain functional statement as the basic for developing the Arabic language curriculum. The purpose of this paper is to provide an understanding that the learning process of Arabic can be integrated with the neuroscience approach. This type of research used library research with content analysis in the form of descriptive analysis using primary sources in the form of bibliographies and scientific journal articles. The results showed that the application of neuroscience can be implemented in the formulation of Arabic curriculum development with a series; 1) optimization of the right and left brain nerve system; 2) integrating the role of the brain into the educational and psychological basis of cognitive aspects (Arabic substance), psychomotor (mastery of Arabic language skills), and affective (attitudes, values, and characters) into Arabic learning; 3) interconnecting these three aspecs into the nature of the objectives, methods, strategies of learning Arabic. On this basis, neuroscience can be implicated in the standard development of Arabic learning curriculum in the modern era.
\end{abstract}

Keywords: Curriculum development, Arabic language, neuroscience

\begin{abstract}
Abstrak
Tulisan ini mendiskusikan tentang kontribusi neurosains dalam pengembangan kurikulum bahasa Arab era modern dengan perkembangan rekonstruksi yang sangat strategis dan praktis. Salah satunya adalah munculnya integrativitas antara nation, brain based learning, dan character building yang menggunakan basis pendekatan neurosains. Pokok dasar kajian ini ialah adanya pernyataan fungsional otak kanan sebagai dasar pengembangan kurikulum bahasa Arab. Adapun tujuan dari tulisan ini adalah untuk memberikan pemahaman bahwa proses pembelajaran bahasa Arab dapat diintegrasikan dengan pendekatan neurosains dengan mengoptimalkan fungsi otak kanan dan otak kiri. Jenis penelitian yang digunakan penelitian pustaka dengan analisis isi konten (analysis content) berupa analisis deskriptif.
\end{abstract}


Metode penelitian menggunakan sumber primer berupa bibliografis dan artikel jurnal ilmiah. Hasil penelitian menunjukkan bahwa aplikasi penerapan neurosains dapat diimplementasikan ke dalam rumusan pengembangan kurikulum bahasa Arab dengan rangkaian; 1) optimalisasi sistem saraf otak kanan dan kiri; 2) mengintegrasikan peran otak ke dalam landasan edukatif dan psikologis berupa aspek kognitif (substansi bahasa Arab), psikomotorik (penguasaan keterampilan bahasa Arab), dan afektif (sikap, nilai, dan karakter) ke dalam rancangan pembelajaran bahasa Arab; 3) menginterkoneksikan ketiga aspek ini ke dalam hakikat tujuan, metode, strategi, dan teknik pembelajaran bahasa Arab. Atas dasar ini, neurosains dapat diimplikasikan ke dalam standar pengembangan kurikulum pembelajaran bahasa Arab era modern.

Kata Kunci: Pengembangan Kurikulum, Bahasa Arab, Neurosains

\section{Pendahuluan}

Pembelajaran bahasa Arab tidak bisa dilepaskan dengan fungsi dan kurikulum sebagai elemen dasar pengembangan dan penyempurnaan yang disesuaikan dengan berbagai faktor yang berkesinambungan, bertahap, dan sistemik untuk mencapai sebuah tujuan. ${ }^{1}$ Tujuan pembinaan kurikulum bahasa Arab menunjuk pada kegiatan yang menghasilkan proses penyusunan, pelaksanaan, penilaian, dan penyempurnaan secara konseptual-filosofis dan organisatoris-sosiologis. ${ }^{2}$

Proses pengembangan kurikulum yang bersifat terbuka mengundang para stakeholder untuk mencari sesuatu dalam ranah sosiologis. Hal ini disebabkan kurangnya kemampuan dalam mengelola kurikulum yang berpola subject centered, ${ }^{3}$ dan komprehensivitas komponen kurikulum bahasa Arab. Salah satu hal yang dapat dimanfaatkan stakeholder dalam mengembangkan kurikulum bahasa Arab adalah penggunaan fungsional otak dan pengetahuan (neuroscience). ${ }^{4}$

Pasalnya, pemanfaatan fungsional otak ini dapat mempengaruhi kinerja akal dan desain pemikiran pendidik dalam mengimplementasikan kurikulum bahasa Arab. Implikasi riil problematika pembelajaran bahasa Arab berpusat

${ }^{1}$ Maksudin Qoim Nurani, Pengembangan Kurikulum Pembelajaran Babasa Arab (Teori dan Praktik) (Yogyakarta: Pascasarjana Fakultas Ilmu Tarbiyah dan Keguruan (FITK) UIN Sunan Kalijaga Yogyakarta, 2016), 226. 2012), 13-15.

${ }^{2}$ Esti Ismawati, Telaab Kurikulum dan Pengembangan Bahan Ajar (Yogyakarta: Ombak,

3 Subject centered merupakan model penyusunan kurikulum yang berlangsung kepada satu mata pelajaran untuk mencapai tujuan kurikuler. Lihat Ismawati, Telaah Kurikulum dan Pengembangan Bahan Ajar, hlm. 17.

${ }^{4}$ Neuroscience berasal dari akar kata neuro (sistem saraf) dan science (ilmu). Jadi, neuroscience dapat didefinisikan sebagai sebuah ilmu yang mempelajari tentang perilaku manusia dengan memberi perhatian pada pusat sistem saraf otak. Imam Hanafi, "Neurosains-Spiritualitas dan Pengembangan Potensi Kreatif,” An-Nuha Vol. 3, No. 1, 2016, hlm. 25. 
pada penggunaan akal secara keseluruhan dari otak manusia. Kesenjangan penggunaan fungsional akal mempengaruhi komplektivitas, dan komprehensivitas pembelajaran bahasa Arab secara riil dalam diskursus pendidikan. ${ }^{5}$

Salah satu dominasi strategi pembelajaran bahasa Arab adalah kesenjangan optimalisasi penggunaan otak kanan dan otak kiri. Ketidakseimbangan inilah menimbulkan masalah yang cukup serius dalam mengembangkan potensi fitrah pembelajaran bahasa Arab ${ }^{6}$. Berdasarkan kecenderungan penggunaan salah satu otak manusia, maka dibutuhkan optimalisasi keseluruhan peran otak kanan dan otak kiri untuk membantu memahami implikasi pembelajaran bahasa Arab dengan cara mengungkap gudang memori dalam bahasa. ${ }^{7}$

Landasan dalam pengembangan kurikulum bahasa Arab harus diorientasikan kepada fakta empirik yang mencerminkan nilai (value) berdasarkan studi pembelajaran bahasa Arab. Dalam hal ini diperlukan analisis kebutuhan pembentukan braind based learning,8 sebagai landasan filosofis pengembangan kurikulum berbasis neurosains. Penempatananatomi fungsi otak dalam konteks pendidikan akan mendapatkan kontribusi transfer knowledge dalam pembelajaran dengan menunjukkan fakta bahwa anatomi otak menyediakan aspek rasional, aspek emosional, dan aspek spiritual. ${ }^{9}$ Melalui tulisan ini, asumsi dasar kajian neurosains dalam ranah pendidikan dan pengembangan kurikulum bahasa Arab membuktikan bahwa seluruh bentuk kinerja transfer pengetahuan dipengaruhi oleh fungsisaraf otak kanan dan otak kiri. Namun pada implikasinya, pengembangan kurikulum bahasa Arab masih bersifat instrumental knowledge yang selalu mengarah pada satu arah pembelajaran serta dominan kepada penggunakan otak kiri.

Berdasarkanasumsi dasar di atas, tujuan tulisan ini yaitu untuk mendiskusikan dan membuktikan peranan otak dalam potensi pengembangan kurikulum bahasa Arab yang sangat menarik perhatian dalam mengimplementasikan proses pembelajaran bahasa Arab pendekatan saraf otak (neurosains). Adapun jenis penelitian ini adalah library researchdengan pendekatan

${ }^{5}$ Maksudin, Metodologi Pengembangan Berpikir Integratif Pendekatan Dialektik, (Yogyakarta: Pustaka Pelajar, 2016), hlm. 216.

${ }^{6}$ Harwintha Yuhria Anjarningsih, Otak Dan Kemampuan Berbabasa, (Yogyakarta: Pustaka Rihama, 2010), hlm. 26-27.

${ }^{7}$ Ibid. hlm. 29.

${ }^{8}$ Brain based learning merupakan teknik-teknik pembelajaran yang mengacu pada kerja otak dengan mengelola gaya belajar, mengolah informasi, pola respon dan penggunaan imajinasi. Lihat dalam Taufik Pasiak, Tuban dalam Otak Manusia, (Bandung: PT Mizan Pustaka, 2012), hlm. 146.

${ }_{9}$ BM Wara Kushartanti, Perkembangan Aplikasi Neurosains Dalam Pembelajaran di TK, (Yogyakarta: Klinik Terapi Fisik FIK UNY, 2003), hlm. 8. 
analisis konten isi (content analysis). ${ }^{10}$ Adapun metode penelitian ini menggunakan sumber data primer yang mengandalkan sumber bibliografis berupa buku-buku dan artikel jurnal ilmiah yang berkaitan dengan tema kajian. Khususnya artikel jurnal ilmiah yang disajikan oleh Muhammad Yusuf tentang kajian otak kanan dalam pengembangan kurikulum bahasa Arab.

Berdasarkan hal ini, asumsi kajian ini berangkat dari tulisan yang dilakukan oleh Muhammad Yusuf tentang otak kanan sebagai basis pengembangandalam kurikulum pembelajaran bahasa Arab untuk menjawab faktor debumanisasi. ${ }^{11}$ Paradigma ini menghendaki sintesisyang dilakukan oleh para ahli untuk mengoptimalisasi sejumlah metode dan strategi dalam pembelajaran bahasa Arab. Sebuah sintesisdiperlukan analisis yang komprehensif dapat menjawab kebutuhan akademik dalam konteks modern. Memasuki abad 21, penggunaan fungsional otak kiri tidak dapat dinafikan keberadaannya sebagai basis pemikiran kebutuhan kurikulum pembelajaran bahasa Arab. Fungsi otak kiri untuk menganalisis kebutuhan kurikulum pembelajaran berkontribusi sebagai pelengkap pada fungsi otak kanan dalam mengaplikasikan kurikulum pembelajaran bahasa Arab. Keduanya melibatkan sistem saraf (neuroscience) untuk mengoptimalkan pengetahuan menjadi pengetahuan yang integral (integral knowledge). Melalui kajian ini, penulis menawarkan konsep pemanfaatan neurosains yang melibatkan fungsional otak kanan dan otak kiri dalam mengembangkan desain kurikulum bahasa Arab secara optimal.

\section{Hasil dan Pembahasan}

\section{A. Pengembangan Kurikulum Bahasa Arab}

Realitas konsep kurikulum ${ }^{12}$ yang mengakar dikalangan akademisi lebih mementingkan kurikulum sebagai subjek akademik. Pandangan ini melihat ilmu pengetahuan lebih mendominasi kepada keseluruhan proses pendidikan. Dengan kata lain dapat diberikan pemahaman bahwa ilmu pengetahuan lebih pro kepada kegiatan pendidikan dibanding dengan kepentingan guru maupun

10 Content Analysis merupakan instrumen yang digunakan untuk mengolah dan menganalisis isi pesan berupa catatan, dokumen, dan sumber data secara objektif dan sistematik. Lihat dalam Sanapiah Faisal, Metodologi Penelitian Pendidikan (Surabaya: Usaha Nasional, 1982) hlm. 133.

${ }^{11}$ Muhammad Yusuf, "Desain Pengembangan Kurikulum Bahasa Arab: Pendekatan Otak Kanan” El-Tsaqafah, Vol. 18, No. 2, 2019, hlm. 149.

12 Istilah kurikulum dalam bahasa Arab disebut dengan Manhaj atau Manabij yang berarti program yang memiliki aktivitas, tujuan, dan peran dalam proses belajar mengajar. Lihat Walid Hudrazindi, al-Manahij at-Ta'limiyyah: Tasmimuba, Wa Tanfidzuha, Taqwimuha, Tathwiruba (Jordan: Modern Book World, n.d.), hlm.15. 
siswa. ${ }^{13}$ Hal ini sejalan dengan pendapat Burhan Yusuf Habibi bahwa ilmu pengetahuan berorientasi kepada komunikasi dan wawasan global sehingga kurikulum sebagai subjek akademik menjadi pusat perhatian pada sistem pembelajaran. ${ }^{14}$ Lebih lanjut, pada tataran kurikulum 2013 dikemukakan bahwa konsep pola pikir pembelajaran dikembangkan dan disempurnakan dari teacher centered menuju learner centered. Pembelajaran berpusat pada peserta didik sehingga dapat menambah wawasan ilmu pengetahuan secara multidimensi dengan gaya belajar siswa (learning style). ${ }^{15}$

Kurikulum yang lebih mementingkan guru dan siswa sebagai objek cenderung memandang ilmu pengetahuan sebagai sumber kebenaran untuk mengembangkan daya intelektetual. Organisator kurikulum subjek akademik bersifat perenialis dan esensialis yang mengembangkan daya intelektual anak untuk mencapai kebenaran-kebenaran yang bersifat universal dan menanamkan kedisiplinan diri dari sumber kebenaran seperti nilai agama yang global. ${ }^{16}$

Bahasa Arab memiliki empat keterampilan bahasa ${ }^{17}$ yang tidak hanya berdiri sebagai instrumen untuk melestarikan ajaran dan nilai agama Islam, tetapi juga berfungsi untuk mendorong pengembangan kecerdasan dan kreativitas peserta didik melalui aspek psikologis (emosi, perasaan, dan kejiwaan) serta pengembangan tenaga yang produktif yang memiliki jiwa pesaing, sabar, rendah hati, menjaga harga diri (self-esteem), dan mampu mengendalikan diri atau nafsu (self-controb. ${ }^{18}$ Sebagai manusia yang sangat membutuhkan komunikasi dalam konteks sosial, intensivitas kecerdasan komunikasi dalam ilmu pengetahuan maupun ilmu agama dapat dibangun melalui bahasa Arab. Sentralisasi bahasa Arab menjadikan sebuah pengantar sebagai dimensi pokok untuk menjaga lisan dan tulisan yang termuat dalam kajian ilmu bahasa Arab. ${ }^{19}$ Kajian bahasa Arab

${ }^{13}$ Lias Hasibuan, Kurikulum Dan Pemikiran Pendidikan (Jakarta: Gaung Persada, 2010), hlm. 27.

${ }^{14}$ Burhan Yusuf Habibi, "Integrasi Kurikulum Bahasa Arab Pesantren Tradisional dan Modern di Madrasah Aliyah Program Keagamaan," Journal of Arabic Studies, 2019, hlm. 161.

15 Salinan Peraturan Menteri Pendidikan dan Kebudayan Republik Indonesia Nomor 36 Tahun 2018 tentang Perubahan atas Peraturan Menteri Pendidikan dan Kebudayaan Nomor 59 Tahun 2014 tentang Kurikulum 2013 Sekolah Menengah Atas/Madrasah Aliyah,” hlm. 2.

${ }^{16} \mathrm{Ibid}$. hlm. 29.

${ }^{17}$ Keterampilan bahasa Arab mencakup kecakapan istima', kalam, qira'ah, dan kitabah yang memiliki unsur-unsur bahasa seperti mufradat, taraakib, dan balaghah. Lihat dalam Mohammad Asrori, Pengembangan Kurikulum di Pesantren, (Malang: UIN Maliki Press, 2013), hlm. 104.

18 Sifat-sifat ini berkaitan dengan pengembangan karakter yang erat kaitannya dengan implikasi neurosains dalam konteks lingkungan pembelajaran, termasuk di dalamnya pembelajaran bahasa Arab. Lihat Erniati, "Pembelajaran Neurosains Dalam Pembentukan Karakter Peserta Didik Pada Pondok Pesantren,” Jurnal Studia Islamika 12, no. 1 (June 2015): hlm. 58.

19 Pendapat Mohammad Asrori sebagaimana mengutip pendapat Abd al-Rahman b. Ibrahim al-Fawzan setidaknya terdapat 13 ilmu bahasa Arab diantaranya yaitu al-Sarf, al-I'rab 
ini kemudian disusun dalam komponen kurikulum yang saling terkait guna merekontruksi tujuan utama pengembangan kurikulum yang membantu siswa untuk mengembangkan kemampuan analisis berbagai ragam masalah kehidupan sosial masyarakat yang secara tidak langsung bergesekan dengan umat manusia. ${ }^{20}$

Kurikulum bahasa Arab memiliki prinsip dasar dalam merancang empat keterampilan berbahasa. Prinsip dasar kurikulum ini kemudian ditetapkan dalam program pembelajaran yang menempati unsur-unsur inti dari pokok kurikulum seperti tujuan pembelajaran, materi bahan ajar, metode pembelajaran, aktivitas pembelajaran, media pembelajaran, dan penilaian pembelajaran.

Unsur-unsur pokok dalam objek formal kurikulum bahasa Arab menjadi ranah pengetahuan kognitif-integratif secara utuh dan konseptual dalam membangun proses interaksi siswa dan guru maupun mahasiswa dan dosen sebagai sumber belajar dan operasional keilmuan pembelajaran bahasa Arab. ${ }^{21}$ Kurikulum yang dikembangkan melalui prinsip dasar harus menjiwai dan mencari integrasi antara nation, brain based learning, dan character building. sinergitas ketiga subprinsip dasar ini akan mengembangkan pengelolan yang optimal inovatif dan organisatoris yang berkelanjutan dalam menyatukan relevansi, sinkronasi, dan efesiensi dasar pengembangan kurikulum bahasa Arab.

Selanjutnya hal yang perlu direkonstruksi dalam pengembangan kurikulum bahasa Arab adalah realitas tujuan dan pengarahan studi orientasi pembelajaran bahasa Arab. Menurut Fathul Mujib orientasi organisatoris studi pendidikan bahasa Arab masih tampak mendua. ${ }^{22}$ Keduanya terpecah belah pada aspek kemahiran dan keilmuan. Aspek kemahiran menuntut kepada kepentingan maharah yang diwajibkan menguasai empat level sekaligus. Sedangkan orientasi keilmuan lebih menjadikan bahasa Arab sebagai instrumen dasar dalam mempelajari bahasa Arab dengan menekankan aspek kemampuan memahami linguistik, kemampuan menerjemahkan, dan kemampuan memberikan inovasi baru dalam memahami struktur pembelajaran bahasa Arab. Realitas empirik inilah kemudian menjadi diskursus yang harus dibenahi dalam memetakan keilmuan bahasa Arab sehingga ditemukannya sebuah connectivity yang dapat membawa perubahan pengorganisasian dalam strategi dan prinsip pengembangan kurikulum bahasa Arab. ${ }^{23}$

(diformulasikan dengan makna nahwu), al-Rasam, al-Ma'ani, al-Bayan, al-Badi', al-'Aruz, al-Qawafi, Qard al-Shi'r, al-Insha', al-Kitabah, Tarikh al-Adab, Matn al-Lughah. Ibid. hlm. 119.

${ }^{20}$ Mohammad Ansyar, Kurikulum Hakikat, Fondasi, Desain, dan Pengembangan, Jakarta: Kencana Prenadamedia Group, 2015), hlm. 286-287.

${ }^{21}$ Maksudin dan QoimNurani, Pengembangan Kurikulum Pembelajaran Bahasa Arab (Teori dan Praktik), (Yogyakarta: Pascasarjana FITK UIN Sunan Kalijaga Yogyakarta, 2018), hlm. 9192.

${ }^{22}$ Fathul Mujib, Rekontruksi Pendidikan Babasa Arab dari Pendekatan Konvensional Ke Integratif Humanis (Yogyakarta: Pedagogia, 2010), hlm. 85.

${ }^{23}$ Ibid. 86. 


\section{B. Pendekatan Global Neurosains}

Salah satu organ tubuh manusia yang dapat mengendalikan seluruh pergerakan aktivitas manusia adalah otak. Sebuah benda kecil yang beratnya tidak lebih dari $1,5 \mathrm{~kg}$ ini memiliki seratus miliar sel saraf aktif (neuron) yang dapat memproses konektivitas untuk berpikir, merasa, melihat, berbicara, dan mencipta ${ }^{24}$. Neuron adalah bagian unit terkecil dari sistem saraf yang menerima dan membawa sinyal melalui kerja listrik dan kimiawi. ${ }^{25}$

Neurosains dapat dikatakan sebagai ilmu yang menjelaskan hubungan otak dan pikiran (brain-mind-connection), atau jiwa dan badan. ${ }^{26}$ Studi saintifik neurosains mengkhususkan pada fungsi dan sistem saraf dalam otak yang kemudian berkembang dan melakukan ekspansi dalam anatomi tubuh manusia. ${ }^{27}$ Secara mendasar neurosains memperhatikan dalam neuro-anatomi otak (struktur otak) dan neurofiologi otak (bagian dan fungsi otak) yang berfungsi memberikan kontribusi penting dalam transfer knowledge secara moral dan rasional. ${ }^{28}$

Sains dalam ilmu pengetahuan diterima dalam kinerja otak melalui cognitivity interpretation ${ }^{29}$ yang kemudian dikembangkan dalam sel-sel aktif mikro dan makro dan memunculkan makna baru dalam ilmu pengetahuan. Dalam perspektif yang luas, neurosains memiliki tujuan penting dalam mempelajari otak manusia yaitu 1) eksplanasi, menerangkan bagaimana sistem saraf dapat bekerja sepanjang hidup, melihat sistem inderawi mengatur respon terhadap stimulus, mengontrol memori kerja dan mengeksplanasi kejadian-kejadian misterius seperti kehendak dan niat; 2) kontrol, mengupayakan pengetahuan tentang otak manusia guna dalam memproses pencegahan dan pengobatan penyakit yang berkaitan dengan sistem saraf.

Para ahli dalam kajian fisiologis hubungan jiwa-badan berusaha memahami dinamika manusia secara utuh untuk melihat kajian objek otak pada level molekuler. ${ }^{30}$ Objek kajian inilah kemudian menimbulkan tiga pilar utama

${ }^{24}$ Najamuddin Muhammad, Memahami Cara Kerja Gelombang Otak Manusia: Menggali Dan Menyikap Sejuta Kedabsyatannya Untuk Kemajuan Diri (Yogyakarta: Diva Press, 2011), hlm. 13.

${ }^{25}$ Taufik Pasiak, Tuban Dalam Otak Manusia, (Bandung: PT Mizan Pustaka, 2012), hlm. 133.

${ }^{26}$ Ibid. hlm. 132.

27 Suyadi, Teori Pembelajaran Anak Usia Dini dalam Kajian Neurosains, (Bandung: PT Remaja Rosdakarya, 2014), hlm. 7.

${ }^{28}$ Warren S. Brown and Brad D. Strawn, The Physical Nature of Christian Life: Neuroscience, Psychology, and the Church (New York: Cambridge University Press, 2012), hln. 47.

29 Cognitivity interpretation adalah sebuah ingatan yang terlatih untuk melihat dan memahami dunia disekeliling untuk menafsirkan dan menjelaskan makna objek yang didengar dan dilihat secara langsung. Lihat Sccott Hagwood, Rahasia Melejitkan Daya Ingat Otak, trans. Abdul Qadir Shaleh, (Yogyakarta: Think, 2019), hln. 45.

30 Taufik Pasiak, Tuban Dalam Otak Manusia, (Bandung: PT Mizan Pustaka, 2012), hlm. 159. 
dalam kajian neurosains yaitu neurogenetika (neuromolekuler), neuroteknologi (instrumentasi), dan neuroenggineering (rekayasa neural).

1. Karakteristik dan Aplikasi Neurosains

Neurosains sebagai ilmu tentang otak yang holistik memahami karakteristik untuk mengatur semua fungsi tubuh dan mengendalikan perilaku manusia yang paling primitif serta bertanggung jawab kepada keseluruhan aktivitas yang melibatkan pikiran, emosi, dan perasaan ${ }^{31}$. Setidaknya terdapat enam karakteristik neurosains yang diaplikasikan dan dapat menyebabkan perubahan perkembangan paradigma dalam teori neuron dan otak, yaitu :

a. Multiple Intelligence ${ }^{32}$, kecerdasan majemuk yang menghubungkan area-area otak pengatur bahasa, musik, motorik, hubungan sosial, dan spiritualis.

b. Emotional Intelligence ${ }^{33}$, kecerdasan emosi yang memegang optimisme, antusiasme, dan motivasi diri yang terintegrasi dengan kecerdasan sosial bertumpu pada otak sosial manusia.

c. Spiritual Intelligence, kecerdasan spiritual yang mengadopsi konsep kecerdasan emosi

d. Adversity Quotient, kecerdasan menghadapi tantangan untuk merespon stimulus melalui aspek psikologi kognitif

e. Brain Based Learning, mengadopsi teknik pembelajaran yang mengacu pada gaya belajar dan kerja otak untuk mengolah informasi dan pola respon

f. Instrumentasi, mengelola potensi berpikir dengan cara mensegmentsi dan mengklasifikasi cara berpikir dengan melibatkan semua aspek kehdupan manusia. ${ }^{34}$

Hasil riset perkembangan neurosains melahirkan proses mental yang tidak hanya sekadar berpacu pada stimulus-respon, tetapi juga melibatkan mekanisme biologis yang dapat memantau kinerja otak ketika melakukan sebuah tindakan yang memungkinkan para ahli memasuki otak manusia (living brain) dan mempelajarinya secara seksama. Hasil riset ini dilakukan dengan dengan teknologi mutakhir dan canggih seperti PET (Possitron Emisson Tomography), SPECT (Single-Photon Emission Computerized Tomography), dan FMRI (Fungsional Magnetic Resonance Imaging), sehingga melahirkan karakteristik dengan mengganti

31 Pangkalan Ide, Menyeimbangkan Otak Kiri dan Otak Kanan, (Jakarta: PT Elex Media Komputindo, 2009), hlm. 12.

32 Teori ini ditemukan oleh Alfred Binet dan kawan-kawan yang berusaha mentransformasikan paradigma lama menuju paradigma baru tentang kecerdasan. Bandingkan dengan Howard Gardner, Frames of Mind: The Theory of Multiple Intelligence, (New York: Basic Book, 1993), hlm. 245.

33 Teori ini dikenalkan oleh Daniel Goleman (1995) yang menyadarkan masyarakat untuk menjaga karakteristik kepribadian. Lihat dalam Lawrence E. Shapiro, Mengajarkan Emotional Intelligence Pada Anake (Jakarta: Gramedia Pustaka Utama, 1997), hlm. 5.

${ }^{34}$ Judith Horstman, The Scientific American Brave New Brain, (San Fransisco: Jhon Wiley \& Son Inc, 2010), hlm. 6. 
paradigma lama ke dalam paradigma baru ke dalam neurosains. Adapun perubahan paradigma dapat dilihat pada tabel dibawah ini: ${ }^{35}$

Perbandingan paradigma lama dan paradigma baru dalam perubahan karakterstik neurosains

\begin{tabular}{|c|c|}
\hline Paradigma Lama & Paradigma Baru \\
\hline Motivasi-motivasi berasal dari luar & Motivasi-motivasi berasal dari dalam \\
\hline Terdapat 4 sifat kepribadian & $\begin{array}{l}\text { Terdapat } 5 \text { sifat kepribadian yaitu } \\
\text { terbuka terhadap hal baru, sifat } \\
\text { berhati-hati, ekstraversi, mudah } \\
\text { bersepakat, dan neurotisme }\end{array}$ \\
\hline Penuaan menurunkan kemampuan & Jika tidak dipakai akan hilang \\
\hline IQ berwajah tunggalkonsep akademik & $\begin{array}{l}\text { IQ berwajah banyak konsep } \\
\text { kecerdasan }\end{array}$ \\
\hline Tidak terdapat perbedaan seks & Terdapat perbedaan seks \\
\hline $\begin{array}{l}\text { Pemeliharaan nature adalah faktor } \\
\text { utama }\end{array}$ & Bawaan nature adalah faktor utama \\
\hline $\begin{array}{l}\text { Bibit penyakit adalah penyebab } \\
\text { penyakit }\end{array}$ & Pikiran dapat mengontrol penyakit \\
\hline Otak bagaikan komputer & Otak bagaikan pabrik obat \\
\hline $\begin{array}{l}\text { Memori dapat dipanggil setelah } \\
\text { melewati episode lengkap }\end{array}$ & $\begin{array}{l}\text { Memori disusun oleh sejumlah } \\
\text { episode dari potongan-potongan } \\
\text { informasi }\end{array}$ \\
\hline Spiritualitas terpisah dari kerja otak & $\begin{array}{l}\text { Spiritualitas berkaitan dengan kerja } \\
\text { otak }\end{array}$ \\
\hline $\begin{array}{l}\text { Pencarian akan makna bukan kegiatan } \\
\text { penting otak manusia }\end{array}$ & $\begin{array}{l}\text { Pencarian makna berkaitan dengan } \\
\text { eksistensi manusia dan merupakan } \\
\text { kegiatan penting otak }\end{array}$ \\
\hline
\end{tabular}

Perubahan paradigma neurosains melahirkan banyak bidang kajian yang seluas-luasnya sehingga para ahli mencoba melakukan eksperimen dan implikasi praktis ke dalam aspek kehidupan manusia dengan berpangku pada sistem neuron.

2. Neurosains dan Implikasinya dalam Pengembangan Kurikulum Bahasa Arab

Istilah pembelajaran dalam kurikulum bahasa Arab tidak bisa dilepaskan oleh unsur perasaan (emosional) yang mengatur pusat informasi pengetahuan secara langsung. Dimensi persepsi dan sensasi berperan penting dalam penerimaan pengetahuan bahasa Arab yang diambil alih oleh sistem saraf dalam otak. Sistem kerja saraf ini dinilai penuh dalam mengkontribusikan pengetahuan

35 Taufik Pasiak, Tuban dalam Otak Manusia, (Bandung: PT Mizan Pustaka, 2012), hlm. 144. 
keilmuan bahasa Arab dari empat keterampilan berbahasa sehingga melahirkan istilah baru dalam ranah pendidikan yaitu Educational Neuroscience. 36 Neurosains pendidikan berfokus pada terma pembelajaran secara umum dengan mengadopsi peran memori, persepsi, dan pikiran serta mengembangkan kerangka kognitif dalam proses belajar mengajar. Tentu peran neurosains dalam pendidikan dapat diimplementasikan pada empat keterampilan berbahasa istima, kalam, qira'ah, dan kitabah dalam proses pembelajaran bahasa Arab yaitu mengandalkan sistem peran memori, persepsi, perasaan, kejiwaan, dan pikiran.

Dilihat dari basis kegiatan pendidikan, sistem saraf otak merupakan bagian yang paling banyak berperan dalam mengaktualisasikan kerangka berpikir dan menangkap informasi baru. Tidak dapat dinafikan bahwa secara tidak langsung peran neurosains dalam pendidikan cukup pesat perkembangannya. Salah satu bukti nyata peran neurosains yang telah terimplikasi pada pendidikan adalah optimalisasi otak sebagai reflektivitas dalam penangkapan dan pengelolaan informasi. Di Amerika, neurosains telah menjadi alat penting bagi perumusan kurikulum pendidikan. Hal ini dikarenakan objek utama pendidikan adalah pengembangan seluruh potensi siswa. Sedangkan potensi siswa bertumpu pada otaknya. ${ }^{37}$ Suyadi dalam bukunya menyebutkan tiga tahapan peran neurosains dalam aspek pendidikan yaitu 1) menangkap dan menyimpan informasi, 2) mengubah informasi menjadi ide baru, 3) mengaplikasikan ide baru untuk menyelesaikan masalah. ${ }^{38}$

Implikasi neurosains pendidikan dalam proses pengembangan kurikulum bahasa Arab dapat dimaksimal dengan optimalisasi saraf otak kanan dan kiri. Optimalisasi otak memerintahkan seluruf sistem saraf untuk bersama-sama melibatkan sebanyak mungkin indera secara serentak sehingga memunculkan gol pembelajaran bahasa Arab yang melibatkan rasional, emosional, perasaan, kejiwaan, dan spiritual. Berikut gambaran integrasi neurosains dalam proses pengembangan kurikulum bahasa Arab.

36 Educational Neuscience menurut Taufik Pasiak adalah konsep pendidikan yang menambahkan pandangan atau perspektif baru dalam ranah neurosains mulai dari pendidikan usia dini hingga pendidikan tinggi. Salah satu pengaplikasian neurosains dalam pendidikan adalah maraknya penggunaan teori dan metode multiple intelligences dan quantum learning yang mendasari kegiatan pembelajaran dengan sistem kerja otak. Ibid. hlm. 140.

37 Citra Trisna Dewi, Nur Wulandari Fitri, and Ovi Soviya, "Neurosains dalam Pembelajaran Agama Islam," Ta'allum: Jurnal Pendidikan Islam 6, no. 2 (November 30, 2018): hlm. 263, https://doi.org/10.21274/taalum.2018.6.2.259-280.

38 Suyadi, Teori Pembelajaran Anak Usia Dini dalam Kajian Neurosains, (Bandung: PT Remaja Rosdakarya, 2014), hlm. 142. 


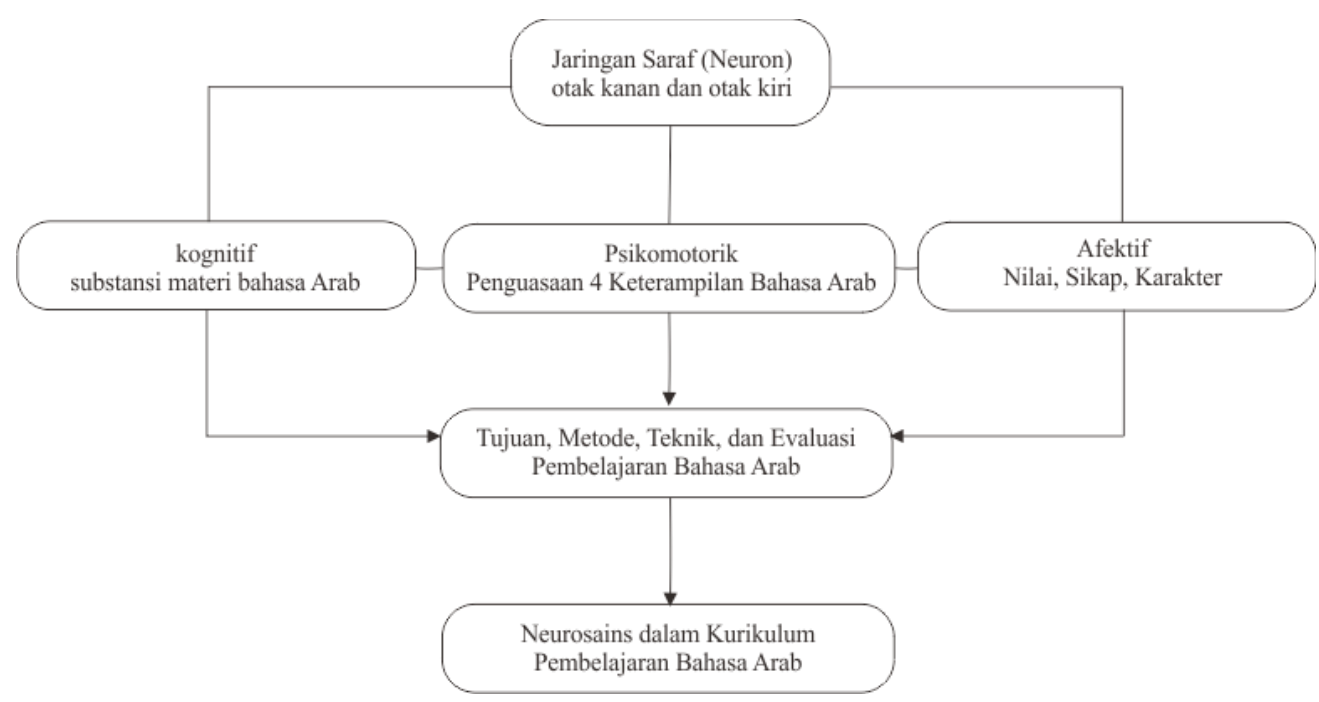

Bagan 1 Skema Neurosains dalam Pengembangan Kurikulum Babasa Arab

Gambar di atas menjelaskan bahwa jaringan saraf otak kanan dan kiri merupakan pusat sentral potensi fitrah yang dimiliki oleh manusia. Jaringan saraf ini terintegrasi oleh aspek kognitif, psikomotorik, dan afektif. Aspek kognitif, psikomotorik, dan afektif memiliki keterkaitan secara utuh untuk memaksimalkan proses pembelajaran bahasa Arab. Aspek kognitif mewakili substansi materi pembelajaran bahasa Arab, aspek psikomotorik mewakili penguasaan empat keterampilan bahasa Arab, dan aspek afektif mewakili sikap atau nilai-nilai karakter dalam proses pembelajaran bahasa Arab. Ketiga aspek ini berproses pada pendekatan otak kanan dan otak kiri yang kemudian terkoneksi dalam tujuan, metode, teknik, dan evaluasi pada pembelajaran bahasa Arab. Untuk memaksimalkan potensi otak, pembelajaran bahasa Arab membutuhkan sistem relaksasi. Rileks disini bukan berarti bentuk meditasi sebagaimana pada proses terapi. Akan tetapi lebih kepada optimalisasi hubungan jiwa dan akal sebelum menerima informasi pembelajaran atau materi pembelajaran bahasa. Relaksasi dapat diaplikasikan dengan cara berdoa sebelum belajar, atau memutar musik tertentu sebelum kegiatan pembelajaran dilaksanakan. Alunan nada yang terdapat pada musik perlahan dapat mengaktifkan gelombang otak sehingga selalu dalam keadaan siaga menerima informasi serta membantu memindahkan informasi ke dalam jangka panjang. ${ }^{39}$ Berdasarkan pernyataan hal ini, sudah selayaknya para ahli pendidikan bahasa Arab dapat memahami cara kerja dan perkembangan alamiah otak pada siswa sehingga otak dapat bergerak secara pure (murni) melahirkan potensi alamiah perkembangan otak siswa melalui neurosains dalam pendidikan bahasa Arab. 


\section{Kontribusi Neurosains dalam Pengembangan Kurikulum Bahasa Arab}

Pengembangan kurikulum bahasa Arab dari masa ke masa dinilai sangat penting dan masih menerima konstruksi-konstruksi pemikiran model kurikulum yang baru dan relevan sesuai dengan kebutuhan masyarakat dan siswa era modern. Hal ini disebabkan perumusan pembelajaran bahasa Arab masih bersifat teaching language (mengajarkan bahasa) bukan teaching about language (mengajarkan tentang bahasa). ${ }^{40}$ Kurikulum sebagai rencana pendidikan mempunyai fungsi pemberian pedoman mengenai jenis, ruang lingkup, dan urutan isi dalam proses pendidikan.

Dengan demikian, kurikulum sangatlah sentral ${ }^{41}$ dalam pengelolaan pusat pendidikan. Keluar dari aspek materi, perumusan kurikulum bahasa Arab harus memperhatikan kebutuhan peserta didik dengan cara melakukan riset awal terlebih dahulu (prior research). Tindakan riset yang sangat mumpuni dalam hal ini adalah tindakan psikologi siswa. ${ }^{42}$

Menurut David A. Sousa dalam kajian neurosains pendidikan, pendidik bukanlah satu-satunya pakar dalam bidang otak. Tetapi pendidik adalah satusatunya profesi yang selalu meraba dan mengubah otak. ${ }^{43}$ Manusia baru menggunakan $5-8 \%$ potensi otak dan $10-15 \%$ pengaplikasian otak dalam ruang lingkup pendidikan. Rumusan pendidikan dalam kurikulum bahasa Arab tidak lepas dari peranan otak yang mempunyai makna penting dari sisi nafs, qalb, dan ar-ruh. Dengan demikian, hakikat pendidikan dalam perspekstif Islam pendekatan neurosains adalah mencetak insan kamil yang terdiri dari berbagai unsur jasmani, rohani, dan akal; IQ/EQ/SQ; serta aspek kognitif, afektif, dan psikomotorik. ${ }^{44}$

Secara psikis kebutuhan peserta didik dalam proses belajar meliputi rasa aman, nyaman, kemampuan, kebebasan, kasih sayang atau perhatian, kesuksesan dan eksistensinya diakui. Rasa aman dan kasih sayang ini merupakan faktor terpenting dalam ruang lingkup pembelajaran. Selanjutnya untuk dapat merumuskan kurikulum bahasa Arab dibutuhkan optimalisasi otak kanan dan otak kiri sehingga tidak terdapat kesenjangan dan menumbuhkan keseimbangan

40 Fathul Mujib, Rekontruksi Pendidikan Bahasa Arab dari Pendekatan Konvensional ke Integratif Humanis, (Yogyakarta: Pedagogia, 2010), hlm. 92.

41 Kurikulum dikatakan sentral karena di dalamnya terdapat bagian-bagian yang dilaksanakan keseluruhan proses belajar meliputi tatanan tujuan pembelajaran, metode pembelajaran, fasilitas pembelajaran sampai kepada tatanan evaluasi pembelajaran. Selaindaripadahaltersebut, kurikulum berfungsi sebagai pedoman pembelajaran antara guru dan siswa. Lihat dalam Ngainun Naim and Ahmad Sauqi, Pendidikan Multikultural Konsep dan Aplikasi (Yogyakarta: Ar-Ruzz Media, 2008), hlm. 190.

${ }^{42}$ Munir, Perencanaan Sistem Pengajaran Bahasa Arab (Jakarta: Kencana, 2017), hlm. 34.

${ }^{43}$ David A. Saosa, Bagaimana Otak Belajar, Keempat (Jakarta: Grasindo, 2012), hlm. x.

${ }^{44}$ Suyadi, Teori Pembelajaran Anak Usia Dini dalam Kajian Neurosains... hlm. 52. 
dalam menentukan tujuan pembelajaran bahasa Arab, metode pembelajaran bahasa Arab, teknik pembelajaran bahasa Arab, dan evaluasi pembelajaran bahasa Arab.

Berikut tawaran penulis pada skema pemanfaatan neurosains dalam komponen dan sistem pembelajaran bahasa Arab:

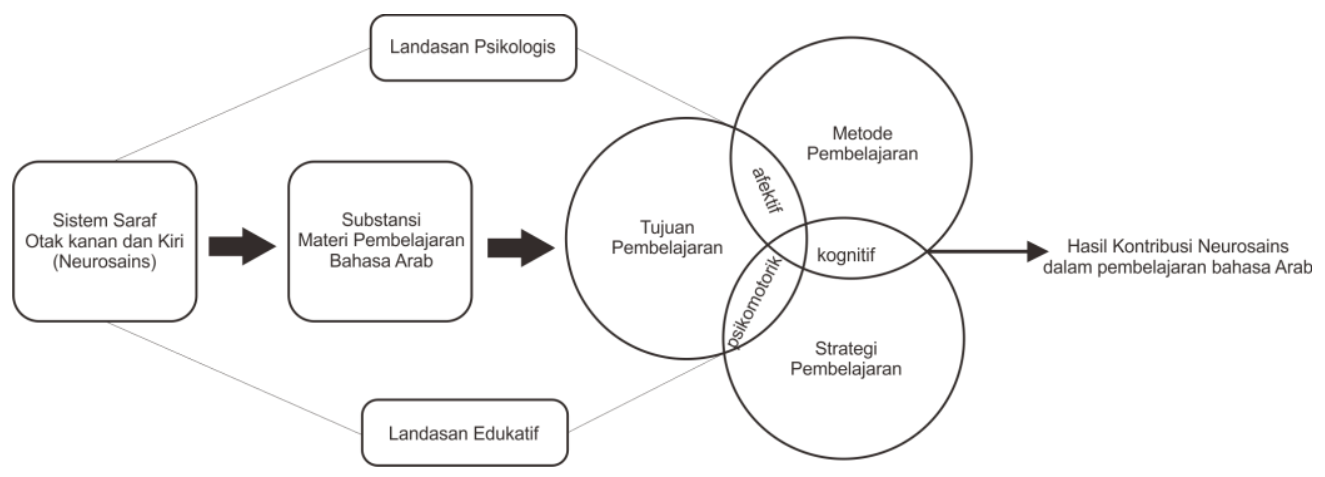

Bagan 2 Pemanfaatan neurosains dalam pembelajaran bahasa Arab

Gambar di atas menjelaskan bahwa seluruh aspek aktivitas pembelajaran bahasa Arab dimulai dari potensi fitrah manusia yaitu sistem saraf otak (neurosains). Sistem saraf ini dibekali oleh landasan edukatif dan landasan psikologis dalam pengelolaan materi pembelajaran bahasa Arab. Landasan edukatif berperan pada aspek kognitif (pengetahuan dasar bahasa Arab) dan psikomotorik (keterampilan berbahasa Arab). Demikian pula landasan psikologis berperan pada aspek afektif yang mengatur pada nilai-nilai sikap, karaker, emosi, perasaan, dan kejiwaan. Fungsi lain dari landasan psikologis dan edukatif ialah menyatukan peran otak kanan dan otak kiri dalam perkembangan emosional quatient (EQ), kemampuan intuitif, dan interaksi belajar serta pengasahan kemampuan logika dalam membaca dan menulis bahasa Arab. Kedua landasan ini saling terintegrasi dalam komponen pembelajaran bahasa Arab yaitu tujuan, metode, dan strategi pembelajaran sehingga dapat menghasilkan daya cipta neurosains dalam pendidikan. Khususnya pendidikan bahasa Arab. Adapun ranah penjelasan komponen pembelajaran sebagai berikut:

1. Tujuan Pembelajaran Bahasa Arab

Bahasa Arab sebagai bahasa kedua dalam kultural masyarakat Indonesia tidaklah sama dengan bahasa Arab pada masyarakat penutur Arab. Perbedaan ini terlihat pada sistem pembelajarannya yang telah diimplementasikan dalam dunia pendidikan bahasa Arab. Proses pembelajaran bahasa Arab harus mempunyai tujuan dan pendekatan yang jelas agar tercipta produk pembelajaran bahasa melalui berbagai pendekatan. ${ }^{45}$

${ }^{45}$ Abdul Halim Hanafi and Amrina, Desain Pembelajaran Bahasa Arab: Membangun Guru Bahasa Arab Yang Professional dan Kompetitif, (Jakarta: Diadit Media Press, 2013), hlm. 19. 
Secara garis besar tujuan pembelajaran bahasa Arab melibatkan dua landasar dasar yaitu landasan edukatif dan landasan psikologis. Keduanya memiliki tujuan yang berbeda sesuai kebutuhan pendidik dan peserta didik. Landasan edukatifdalam pembelajaran bahasa Arab erat kaitannya dengan sistem dan strategi pembelajaran. Landasan psikologis berkaitan dengan potensi, kemampuan, kebutuhan, minat, dan bakat serta kepuasan batin siswa dalam mempelajari bahasa $\mathrm{Arab}^{46}$. Tujuan pembelajaran bahasa Arab dalam perspektif Muhajir ialah memberikan kaidah berbahasa meliputi maharah istima', kalam, qira'ah, dan kitabah serta dapat mengintegrasikan dengan berbagai bidang keilmuan lain. ${ }^{47}$ Meskipun demikian, bentuk tujuan pembelajaran bahasa Arab melibatkan otak sebagai pusat sentral berpikir. Adapun tujuan pembelajaran bahasa Arab dengan peningkatan fungsional otak dan pengetahuan adalah tujuan pembelajaran yang berorientasi kepada neurolinguistik. ${ }^{48}$ Neurolinguistik dalam kajian ini yaitu proses pengembangan bahasa Arab yang terintegrasi oleh neurosains.

Tujuan pembelajaran ini meranah pada kompetensi sikap dan pengetahuan siswa agar mampu berpikir secara rasional dari permasalahanpermasalahan faktual dengan keterampilan bahasa. Termasuk konteks dalam memahami bahasa agama Islam yang menggunakan bahasa Arab melalui alQur'an, al-Hadits, dan buku-buku yang berbahasa Arab. Ketercapaian yang lain dalam rumusan tujuan ini adalah membantu pengembangan wawasan disiplin ilmu yang sedang ditekuni secara mendalam dan lebih detail. Proses pembelajaran bahasa Arab dengan penekatan neurolinguistik sebagai instrumen tujuan dengan mudah dapat meningkatkan pemahaman, pengamatan, dan respon dalam kemahiran berbahasa dalam konteks kekinian.

2. Metode pembelajaran Bahasa Arab

Kehadiran pendekatan dan sistem pembelajaran dan pengajaran bahasa Arab menghasilkan proses dan produk yang berbeda. Hal ini dipengaruhi oleh pendekatan metode pembelajaran bahasa Arab yang beragam. Adapun metode pembelajaran bahasa Arab yang penulis tawarkan sesuai dengan pendekatan neurosains adalah metode mind map.49 Penetapan metode ini sebagai

${ }^{46}$ Muhbib Abdul Wahab et al., "Standarisasi Kompetensi Babasa Arab bagi Calon Sarjana Perguruan Tinggi Keagamaan Islam Negeri," Arabiyat: Jurnal Pendidikan Bahasa Arab dan Kebahasaaraban 5, no. 1 (June 3, 2018): 38-64, https://doi.org/10.15408/a.v5i1.6691.

${ }^{47}$ Muhajir, Arah Baru Pengajaran Bahasa Arab "Filsafat Bahasa, Metode, Dan Pengembangan Kurikulum" (Yogyakarta: FITK UIN Sunan Kalijaga, 2017).

${ }^{48}$ Neurolinguistik merupakan model pembelajaran yang mempelajari bagaimana bahasa direpresentasikan dan diproses oleh otak manusia. Lihat Harwintha Yuhria Anjarningsih, Otak dan Kemampuan Babasa, (Yogyakarta: Pustaka Rihama, 2010), hlm. 95.

${ }^{49}$ Metode Mind Map dicetuskan oleh Tony Buzan yang berfungsi untuk mencurahkan segala bentuk pikiran dalam sebuah skema atau gambar secara lebih sistematis. Metode ini melibatkan otak kanan dan otak kiri untuk menyajikan informasi dengan dua cara yaitu pemikiran yang diungkapkan oleh bahasa melibatkan otak analitis atau otak kiri dan 
penyempurnaan metode psychological method yang berfokus pada salah satu pendekatan otak dalam pembelajaran bahasa Arab yaitu otak kanan. Peran mind map sebagai kerangka dasar berpikir tidak hanya melibatkan perkembangan mental dan asosiasi pemikiran sebagaimana yang telah dikemukakan oleh Muhammad Yusuf dalam pembelajaran bahasa Arab. ${ }^{50}$ Akan tetapi melibatkan landasan edukatif dengan memperhatikan kesukaan dan kepuasaan batin peserta didik.

Metode mind map dalam pembelajaran bahasa Arab pula tidak hanya terfokus pada mata sebagai panca indera, pikiran, dan hati. Akan tetapi seluruh pancaindra yang termuat dalam insan kamil untuk merealisasikan rasionalitas, emosional, dan nilai-nilai spiritual dalam pembelajaran. Tentu sisi integrasi dan interkoneksi pengetahuan sangat dibutuhkan agar metode pembelajaran bahasa Arab tidak menjadi sebuah wacana semata. Rangkaian sistemik integrasi dan interkoneksi dalam pembelajaran bahasa Arab diharapkan mampu membentuk sebuah karakter keilmuan holistik, menyatukan perpaduan cara berpikir otak yang integratif-komprehensif, dan membentuk mindset berpikir yang mewakili reflektivitas kerja otak dalam pembelajaran. Pembelajaran bahasa Arab dengan pendekatan metode mind map sangat membantu meningkatkan motivasi dalam bidang neurosains pendidikan. Hal ini diperkuat oleh hasil penelitian Endah dan Nashirudin bahwa mind map merupakan metode yang mampu mengoptimalkan kedua belah otak yang dapat mengatur fungsi mental dan pengolahan informasi dalam pembelajaran bahasa Arab. ${ }^{51}$

3. Teknik dan Strategi Pembelajaran Bahasa Arab

Aspek terpenting dalam pembelajaran bahasa Arab adalah implementasi kurikulum bahasa Arab yang telah dirumuskan dengan pendekatan dan tujuan pembelajaran bahasa Arab. Implementasi pembelajaran dibutuhkan teknik dan strategi yang sinergis dari metode yang telah ditentukan sehingga proses pembelajaran menjadi kreatif, efektif, dan menyenangkan. ${ }^{52}$ Teknik pembelajaran bahasa Arab menekankan pada aspek PAIKEM ${ }^{53}$ yang menciptakan suasana

penggambaran yang melibatkan otak kanan. Lihat Suyadi, Teori Pembelajaran Anak Usia Dini dalam Kajian Neurosains.... hlm. 180-181.

50 Muhammad Yusuf, "Desain Pengembangan Kurikulum Bahasa Arab: Pendekatan Otak Kanan” El-Tsaqafah, Vol. 18, No. 2, 2019, hlm. 158.

${ }^{51}$ Endah and Nasiruddin, "Eksperimentasi Metode Mind Map Pada Pembelajaran Nabwu Bahasa Arab Untuk. Meningkatkan Hasil Belajar Siswa," Al-Mahāra Jurnal Pendidikan Bahasa Arab 05, no. 01 (2019): hlm. 88-89, https://doi.org/10.14421/almahara.2019.051-05.

52 Ismail, Strategi Pembelajaran Agama Islam Berbasis PAIKEM (Semarang: Rasial Media Group, 2008), hlm 46.

${ }^{53}$ PAIKEM merupakan singkatan dari pembelajaran aktif, inovatif, kreatif, efektif, dan menyenangkan. Dikatakan demikian karena proses pembelajaran hendaknya dapat mengembangkan kreativitas pendidik dan peserta didik dalam ruang lingkup pembelajaran. Lihat dalam Nur Sholeh and Ulin Nuha, Pengembangan Kurikulum Babasa Arab Analisis dan Panduan Kurikulum Babasa Arab Sesuai KTSP, (Yogyakarta: Diva Press, 2013), hlm. 191. 
pembelajaran menjadi aktif bertanya, mempertanyakan, dan mengemukakan gagasan. Teknik pembelajaran ini dalam perspektif neurosains dapat diimplementasikan dalam metode pembelajaran berbasis mind map. Aplikasi penerapan pembelajaran aktif dengan metode mind map dengan mengaktualisasikan beberapa langkah yaitu ${ }^{54}$ 1) Guru menyampaikan kompetensi yang ingin dicapai, 2) Guru mengemukakan konsep atau permasalahan yang akan ditanggapi oleh siswa atau sebaliknya permasalahan yang mempunyai alternatif jawaban, 3) membentuk kelompok yang anggotanya 2-3 orang per kelompok, 4) tiap-tiap kelompok menginventarisasi atau mencatat alternatif jawaban hasil diskusi, 5) tiap kelompok (diacak sesuai kelompok tertentu) membaca hasil diskusi dan guru mencatat di papan tulis serta mengelompokkan sesuai dengan kebutuhan guru, dan 6) dari data-data di papan, siswa diminta membuat sebuah kesimpulan dan guru memberikan bandingan dengan konsep yang disediakan oleh guru.

Strategi di atas tersirat bahwa guru dan siswa menggunakan hukum silang otak yang berpedoman bahwa pandangan objek sebelah kanan dapat diproses dengan otak sebelah kiri serta pandangan sebelah kiri dapat diproses oleh otak sebelah kanan. Dengan demikian dalam proses pembelajaran akan terjadi optimalisasi otak kanan dan otak kiri secara maksimal, konseptual, dan rasional. Bandingan konsep pembelajaran bahasa Arab antara siswa dan guru dapat ditemukan make a match55 setelah teknik pembelajaran dilaksanakan. Meskipun demikian, teknik bergantung pada guru, guru diharapkan mampu membuat proses kreatif dalam ruang lingkup pembelajaran sehingga tujuan pembelajaran bahasa Arab yang melibatkan landasan psikologis dan proses edukatif dapat terlaksana sesuai alur pembelajaran yang telah direncanakan.

4. Evaluasi Pembelajaran Bahasa Arab

Sebuah proses pendidikan dalam pengembangan pembelajaran dari proses kurikulum yang telah dirancang dengan sedemikian rupa tidak akan luput dengan evaluasi. Evaluasi pembelajaran digunakan agar pengembang baik itu dalam rangkaian struktur organisatoris kurikulum pendidikan maupun pendidik dapat terus berinovasi sesuai karakteristik dan kebutuhan masyarakat ${ }^{56}$. Evalualasi dalam pembelajaran bahasa $\mathrm{Arab}^{57}$ pendekatan neurosains yaitu dengan menggunakan evaluasi sumatif yang melihat keseluruhan sistem

${ }^{54}$ Ibid. hlm. 194.

${ }_{55}$ Make a match adalah mencari pasangan konsep pembelajaran yang dilakukan antara guru dan siswa sehingga terjadi connectivity (hubungan) konsep yang jelas. Lihat, Ibid. hlm. 194195.

${ }^{56}$ M. Ainun, Evaluasi Dalam Pembelajaran Bahasa Arab, (Malang: Misykat, 2006).

${ }^{57}$ Fitri Mawaddah Bako et al., "Pengawasan dan Evaluasi Program Bahasa Arab di Pondok Pesantren," Arabi: Journal of Arabic Studies Vol 3, No. 1 (June 30, 2018): hlm. 69, https://doi.org/10.24865/ajas.v3i1.72. 
perencanaan, perancangan, hingga pelaksanaan secara tuntas dari organisasi kurikulum bahasa Arab yang telah diimplementasikan.

\section{Penutup}

Dari berbagai penjelasan di atas, penulis dapat menyimpulkan bahwa kajian neurosains dalam pengembangan kurikulum bahasa Arab menggunakan hukum silang otak. Hukum ini dimonitori oleh landasan edukatif dan psikologis yang melibatkan proses kognitif, afektif, dan psikomotorik. Proses ini kemudian dipadukan dalam tujuan, metode, teknik, dan strategi pembelajaran bahasa Arab sehingga pengetahuan yang dihasilkan oleh sistem saraf (neurosains) pada kurikulum pembelajaran bahasa Arab menjadikan pengetahuan yang integral (integral knowledge). Selain itu, pendekatan neurosains pada kurikulum bahasa Arab sejalan dengan prinsip yang dijalankan oleh kurikulum baru yaitu pola pikir pembelajaran dikembangkan dan disempurnakan dengan pembelajaran yang berpusat pada peserta didik (learner centered).Pola pikir ini melibatkan sistem saraf otak kanan dan otak kiri yang berperan untuk memberikan gambaran objek dan analisis sehingga dapat menjadikan siswa lebih kreatif dan inovatif dalam mengelola pembelajaran. Dengan demikian siswa mendapatkan pengetahuan multidimensi yang tidak hanya terpaku oleh materi saja, tetapi juga pada aspek keterampilan dan nilai afektif dalam proses pembelajaran bahasa Arab. 


\section{Bibliografi}

Ainun, M. Evaluasi Dalam Pembelajran Bahasa Arab. Malang: Misykat, 2006.

Anjarningsih, Harwintha Yuhria. Otak Dan Kemampuan Berbahasa. Yogyakarta: Pustaka Rihama, 2010.

Ansyar, Mohammad. Kurikulum Hakikat, Fondasi, Desain, Dan Pengembangan. Jakarta: Kencana Prenadamedia Group, 2015.

Asrori, Mohammad. Pengembangan Kurikulum Di Pesantren. Malang: UIN Maliki Press, 2013.

Bako, Fitri Mawaddah, Faiqatul Masrurah, Friske Tuli, and Desiy Arifah. "Pengawasan Dan Evaluasi Program Bahasa Arab Di Pondok Pesantren." Arabi: Journal of Arabic Studies 3, no. 1 (June 30, 2018). https://doi.org/10.24865/ajas.v3i1.72.

Dewi, Citra Trisna, Nur Wulandari Fitri, and Ovi Soviya. "Neurosains dalam Pembelajaran Agama Islam." Ta'allum: Jurnal Pendidikan Islam 6, no. 2 (November 30, 2018). https://doi.org/10.21274/taalum.2018.6.2.259280.

Endah, and Nasiruddin. "Eksperimentasi Metode Mind Map Pada Pembelajaran Nahwu Bahasa Arab Untuk Meningkatkan Hasil Belajar Siswa." Al Mabāra Jurnal Pendidikan Babasa Arab 05, no. 01 (2019). https://doi.org/10.14421/almahara.2019.051-05.

Erniati. "Pembelajaran Neurosains Dalam Pembentukan Karakter Peserta Didik Pada Pondok Pesantren.” Jurnal Studia Islamika 12, no. 1 (June 2015).

Faisal, Sanapiah. Metodologi Penelitian Pendidikan. Surabaya: Usaha Nasional, 1982.

Gardner, Howard. Frames of Mind: The Theory of Multiple Intelligence. New York: Basic Book, 1993.

Habibi, Burhan Yusuf. "Integrasi Kurikulum Bahasa Arab Pesantren Tradisional Dan Modern Di Madrasah Aliyah Program Keagamaan." Journal of Arabic Studies, 2019, 17.

Hagwood, Sccott. Rahasia Melejitkan Daya Ingat Otak. Translated by Abdul Qadir Shaleh. Yogyakarta: Think, 2019.

Hanafi, Abdul Halim, and Amrina. Desain Pembelajaran Babasa Arab: Membangun Guru Bahasa Arab Yang Professional Dan Kompetitif. Jakarta: Diadit Media Press, 2013.

Hanafi, Imam. "Neurosains-Spiritualitas Dan Pengembangan Potensi Kreatif," An-Nuha Vol. 3, No. 1, 2016. 
Hasibuan, Lias. Kurikulum Dan Pemikiran Pendidikan. Jakarta: Gaung Persada, 2010.

Horstman, Judith. The Scientific Amirican Brave New Brain. San Fransisco: Jhon Wiley \& Son Inc, 2010.

Hudrazindi, Walid. Al Manabij At-Ta'limiyyah: Tasmimuha, Wa Tanfidzuba, Taqwimuba, Tathwiruha. Jordan: Modern Book World, n.d.

Ide, Pangkalan. Menyeimbangkan Otak Kiri Dan Otak Kanan. Jakarta: PT Elex Media Komputindo, 2009.

Ismail. Strategi Pembelajaran Agama Islam Berbasis PAIKEM. Semarang: Rasial Media Group, 2008.

Ismawati, Esti. Telaah Kurikulum dan Pengembangan Bahan Ajar. Yogyakarta: Ombak, 2012.

Kushartanti, BM Wara. Perkembangan Aplikasi Neurosains Dalam Pembelajaran Di TK. Yogyakarta: Klinik Terapi Fisik FIK UNY, 2003.

Maksudin. Metodologi Pengembangan Berpikir Integratif Pendekatan Dialektik,. Yogyakarta: Pustaka Pelajar, 2016.

Muhajir. Arah Baru Pengajaran Bahasa Arab "Filsafat Bahasa, Metode, Dan Pengembangan Kurikulum.” Yogyakarta: FITK UIN Sunan Kalijaga, 2017.

Muhammad, Najamuddin. Memahami Cara Kerja Gelombang Otak Manusia: Menggali Dan Menyikap Sejuta Kedahsyatannya Untuk Kemajuan Diri. Yogyakarta: Diva Press, 2011.

Mujib, Fathul. Rekontruksi Pendidikan Bahasa Arab Dari Pendekatan Konvensional Ke Integratif Humanis. Yogyakarta: PEDAGOGIA, 2010.

Munir. Perencanaan Sistem Pengajaran Bahasa Arab. Jakarta: Kencana, 2017.

Naim, Ngainun, and Ahmad Sauqi. Pendidikan Multikultural Konsep Dan Aplikasi. Yogyakarta: Ar-Ruzz Media, 2008.

Pasiak, Taufik. Tuhan Dalam Otak Manusia. Bandung: PT Mizan Pustaka, 2012.

Qoim Nurani, Maksudin. Pengembangan Kurikulum Pembelajaran Bahasa Arab (Teori dan Praktik). Yogyakarta: Pascasarjana Fakultas Ilmu Tarbiyah dan Keguruan (FITK) UIN Sunan Kalijaga Yogyakarta, 2016.

S. Brown, Warren, and Brad D. Strawn. The Physical Nature of Christian Life: Neuroscience, Psychology, and the Church. New York: Cambridge University Press, 2012.

Saosa, David A. Bagaimana Otak Belajar. Keempat. Jakarta: Grasindo, 2012. 
Shapiro, Lawrence E. Mengajarkan Emotional Intelligence Pada Anak. Jakarta: Gramedia Pustaka Utama, 1997.

Sholeh, Nur, and Ulin Nuha. Pengembangan Kurikulum Bahasa Arab Analisis Dan Panduan Kurikulum Bahasa Arab Sesuai KTSP. Yogyakarta: Diva Press, 2013.

Suyadi. Teori Pembelajaran Anak Usia Dini Dalam Kajian Neurosains. Bandung: PT Remaja Rosdakarya, 2014.

Wahab, Muhbib Abdul, Aziz Fahrurrozi, Tulus Musthafa, and Syamsul Arifin. "Standarisasi Kompetensi Bahasa Arab Bagi Calon Sarjana Perguruan Tinggi Keagamaan Islam Negeri." Arabiyat: Jurnal Pendidikan Bahasa Arab dan Kebahasaaraban 5, no. 1 (June 3, 2018). https://doi.org/10.15408/a.v5i1.6691.

Yusuf, Muhammad. "Desain Pengembangan Kurikulum Bahasa Arab: Pendekatan Otak Kanan” El-Tsaqafah, Vol. 18, No. 2. (2019). 